\title{
Arabidopsis thaliana FLOWERING LOCUS D Is Required for Systemic Acquired Resistance
}

\author{
Vijayata Singh, ${ }^{1}$ Shweta Roy, ${ }^{1}$ Mrunmay Kumar Giri, ${ }^{1}$ Ratnesh Chaturvedi, ${ }^{2}$ Zulkarnain Chowdhury, ${ }^{2}$ \\ Jyoti Shah, ${ }^{2}$ and Ashis Kumar Nandi ${ }^{1}$ \\ ${ }^{1}$ School of Life Sciences, Jawaharlal Nehru University, New Delhi -110067, India; ${ }^{2}$ Department of Biological Sciences and \\ Signaling Mechanisms in Plants Cluster, University of North Texas, Denton 76203, U.S.A.
}

Submitted 6 April 2013. Accepted 23 May 2013.

Localized infection in plants often induces systemic acquired resistance (SAR), which provides long-term protection against subsequent infections. A signal originating in the SAR-inducing organ is transported to the distal organs, where it stimulates salicylic acid (SA) accumulation and priming, a mechanism that results in more robust activation of defenses in response to subsequent pathogen infection. In recent years, several metabolites that promote long-distance SAR signaling have been identified. However, the mechanism or mechanisms by which plants perceive and respond to the SAR signals are largely obscure. Here, we show that, in Arabidopsis thaliana, the FLOWERING LOCUS D $(F L D)$ is required for responding to the SAR signals leading to the systemic accumulation of $\mathrm{SA}$ and enhancement of disease resistance. Although the fld mutant was competent in accumulating the $S A R$-inducing signal, it was unable to respond to the $S A R$ signal that accumulates in petiole exudates of wild-type leaves inoculated with a SAR-inducing pathogen. Supporting FLD's role in systemic SAR signaling, we observed that dehydroabietinal and azelaic acid, two metabolites that, in wild-type plants, promote SAR-associated systemic accumulation of SA and priming, respectively, were unable to promote $S A R$ in the fld mutant. FLD also participates in flowering, where it functions to repress expression of the flowering repressor FLOWERING LOCUS C (FLC). However, epistasis analysis indicates that FLD's function in SAR is independent of FLC.

Recognition by plants of molecular patterns that are conserved among various microbes results in the activation of pathogen-associated molecular pattern-triggered immunity (PTI), which contributes to basal resistance against pathogens, thus limiting the extent of pathogen growth (Spoel and Dong 2012). However, the impact of PTI on curtailing pathogen growth is weak compared with that of effector-triggered immunity (ETI), which is induced upon recognition by the plant of race-specific effectors produced by avirulent (Avr) pathogens. In addition to PTI and ETI, which locally control pathogen growth, plants also have the ability to enhance resis-

Corresponding author: A. K. Nandi; Telephone: +91-11-26704152; Email: ashis_nandi@mail.jnu.ac.in, ashis_nandi@yahoo.com

* The $\boldsymbol{e}$-Xtra logo stands for "electronic extra" and indicates that seven supplementary figures and two supplementary tables are published online.

(C) 2013 The American Phytopathological Society tance status of the distal pathogen-free organs in response to a prior infection elsewhere on the foliage. This mechanism, which is termed systemic acquired resistance (SAR), confers long-term protection throughout the foliage against subsequent infections by a variety of pathogens (Chaturvedi and Shah 2007; Durrant and Dong 2004; Sticher et al. 1997). In plants exhibiting SAR, defense responses are primed for stronger activation in response to subsequent infections (Shah and Zeier 2013). Indeed, under conditions of high disease pressure, SAR confers a fitness advantage (Traw et al. 2007). Studies in Arabidopsis thaliana have indicated that the protective effect of SAR can be epigenetically transmitted to the next generation (Luna et al. 2012).

SAR is accompanied by an increase in salicylic acid (SA) content and elevated expression of the SA-inducible PATHOGENESIS-RELATED 1 (PRl) gene. This increase in expression of $P R I$ has been used as a molecular marker for monitoring SAR activation (Chaturvedi and Shah 2007; Durrant and Dong 2004). SA signaling is critical for the manifestation of SAR-conferred enhanced disease resistance. In Arabidopsis, limiting SA accumulation, either due to a block in its synthesis in the isochorismate synthase 1 (ics1) mutant or by expressing the bacterial $n a h G$ gene-encoded salicylate hydroxylase that converts SA to catechol, resulted in the attenuation of SARconferred resistance (Lawton et al. 1995; Wildermuth et al. 2001). Similarly, SAR was also attenuated in NahG tobacco (Vernooij et al. 1994). Also required for SAR is NPR1, a transcription co-regulator of SA-responsive genes, which itself is activated by SA binding (Spoel and Dong 2012; Wu et al. 2012).

Activation of SAR is dependent on the ability of the primary pathogen-infected organs to efficiently communicate with the rest of the foliage. Girdling experiments in tobacco and cucumber suggested that the phloem is the likely route for transport of long-distance signals that mediate this communication (Guedes et al. 1980; Tuzun and Kuc 1985). Indeed, a SARinducing activity can be recovered in vascular sap-enriched petiole exudates (Pex) collected from Arabidopsis leaves inoculated with a SAR-inducing Avr pathogen (Chaturvedi et al. 2008, 2012; Jung et al. 2009; Maldonado et al. 2002). When locally applied to lower leaves, Avr-Pex collected from Arabidopsis leaves was effective in promoting SAR in the distal leaves. Although SA is present in vascular sap, it was previously shown not to be the long-distance translocated SAR signal (Pallas et al. 1996; Rasmussen et al. 1991; Vernooij et al. 1994).

In recent years, several metabolites potentially involved in long-distance signaling in SAR have been described (Dempsey and Klessig 2012). Methyl salicylate (MeSA) was reported as 
a long-distance SAR signal in tobacco plants infected with Tobacco mosaic virus (Park et al. 2007). It was suggested that MeSA produced from SA in the virus-inoculated leaves was transported to the distal leaves, where it was hydrolyzed by the MeSA esterase activity of SA-BINDING PROTEIN 2 (SABP2) to release SA; which, in turn, could promote downstream defenses (Park et al. 2007). Similarly, MeSA has also been suggested to function as a long-distance SAR signal in potato and Arabidopsis (Manosalva et al. 2010; Vlot et al. 2008). However, other studies have seen no role, or a weak function, for MeSA in SAR in Arabidopsis (Attaran et al. 2009; Chaturvedi et al. 2012). It has been suggested that light is a likely factor that influences the overall contribution of MeSA as a long-distance signal in SAR, thus explaining some of the variability in the requirement of MeSA in SAR (Liu et al. 2011). Dehydroabietinal (DA), an abietane diterpenoid, has been suggested as another long-distance signal in SAR (Chaturvedi et al. 2012). DA was purified as a SAR-inducing metabolite from Arabidopsis Avr-Pex. DA applied to lower leaves of Arabidopsis is rapidly translocated to the distal leaves, where it promotes SA accumulation and enhanced disease resistance. Compared with MeSA and DA, which promote systemic disease resistance by promoting systemic SA accumulation, azelaic acid (Aza), a 9$\mathrm{C}$ dicarboxylic acid, and the lysine metabolite pipecolic acid are proposed to promote priming of defenses during SAR (Jung et al. 2009; Navarova et al. 2012). Aza and DA, when applied together, had a synergistic effect on the activation of SAR in Arabidopsis (Chaturvedi et al. 2012). Glycerol-3-phosphate $(\mathrm{G} 3 \mathrm{P})$ is another metabolite that has been suggested to participate in long-distance SAR signaling (Chanda et al. 2011). G3P levels were found to increase in Avr-Pex; and G3P, when applied with Pex, was capable of systemically activating disease resistance. The involvement of a G3P-dependent factor in long-distance signaling is also supported by earlier observations that the G3P-synthesizing dihydroxyacetone phosphate reductase, encoded by SUPPRESSOR OF FATTY ACID DESATURASE-DEFICIENCY 1 (SFD1), was required for the accumulation or translocation of the SAR signal (Chaturvedi et al. 2008; Lorenc-Kukula et al. 2012; Nandi et al. 2004). The G3P-dependent factor has been suggested to facilitate longdistance movement of DEFECTIVE IN INDUCED-RESISTANCE 1 (DIRl) (Chanda et al. 2011), a putative lipid-transfer protein that is required for the activation of SAR (Maldonado et al. 2002). Like the $s f d 1$ mutant, Avr-Pex collected from the dirl mutant were unable to induce SAR when applied to wildtype (WT) plants (Chaturvedi et al. 2008; Maldonado et al. 2002). However, when co-infiltrated into lower leaves of WT plants, sfdl plus dirl Avr-Pex were competent in inducing SAR (Chaturvedi et al. 2008). Presence of SFD1 also enhances the effectiveness of DA, and DIR1 is required for DA-induced systemic disease resistance, thus suggesting interaction between DIR1-, SFD1-, and DA-mediated signaling (Chaturvedi et al. 2012).

Here, we show that the FLOWERING LOCUS D (FLD) is required for Arabidopsis to respond to the SAR signals leading to the systemic accumulation of SA and priming the robust activation of SA signaling in response to subsequent exposure to a virulent pathogen. Although $F L D$ is also involved in flowering as a negative regulator, FLOWERING LOCUS C (FLC) expression, we provide evidence that $F L D$ function in SAR does not involve $F L C$.

\section{RESULTS}

The reduced systemic immunity 1 mutant is defective in SAR.

To identify genes involved in SAR signaling, a genetic screen was set up for mutants that were unable to activate
SAR-conferred enhanced disease resistance against the virulent pathogen Pseudomonas syringae pv. maculicola ES4326. To induce SAR, three fully expanded rosette leaves were infiltrated (primary treatment) with $P$. syringae pv. tomato DC3000 that carried the AvrRpt2 gene (Avr-Pst). Plants that received a primary treatment consisting of $10 \mathrm{mM} \mathrm{MgCl}$ (mock), which was used to prepare the bacterial suspension, provided the negative control for SAR. Three days after the primary treatment, the distal leaves of these plants were challenged with $P$. syringae pv. maculicola. Bacterial numbers in these leaves were determined 3 days postinfiltration (dpi). The SAR-deficient mutant reduced systemic immunity 1 (rsil) mutant was uncovered after screening about $1,800 \mathrm{M}_{2}$ plants. As expected, SAR was induced in the WT plants, thus resulting in lower numbers of $P$. syringae pv. maculicola in plants that received a primary treatment consisting of the SAR-inducing Avr-Pst, than in plants that received a first mock treatment (Fig. 1A; Supplementary Fig. S1). Compared with the WT, SAR-conferred resistance was compromised in the rsil mutant (Fig. 1A).

P. syringae pv. maculicola numbers were comparable in the distal leaves of WT and rsil plants that received a first mock treatment, suggesting that the mutation in rsil does not compromise basal resistance against $P$. syringae pv. maculicola (Fig. 1A). Additional experiments in which the virulent pathogen $P$. syringae pv. tomato DC3000 was infiltrated into leaves of WT and rsil plants that did not receive the primary treatment also indicated comparable population size in the WT and rsil mutant, thus confirming that basal resistance against these virulent pathogens was not compromised in the rsil mutant (Fig. 1B). Similarly, resistance against Avr-Pst was not compromised in the rsil mutant (Fig. 1C). Thus, RSI1 is required for SAR but not for local resistance.

\section{Mutant rsi1 is a missense allele of $F L D$.}

During the vegetative phase of growth, the rsil mutant was morphologically indistinguishable from the WT plant (Supplementary Fig. S2A). However, compared with the WT, rsil plants exhibited a delay in transition from vegetative to the reproductive stage. The delayed flowering phenotype of rsil segregated as a single locus that was recessive to the WT RSII allele in $\mathrm{F}_{2}$ progenies derived from a cross between rsil and WT accession Columbia (Col-0), as well as from a rsil $\times$ WT accession Wassilewskija (Ws) cross (Supplementary Table S1). The $\mathrm{F}_{3}$ progeny of $\mathrm{F}_{2}$ plants showing a delayed flowering phenotype showed a SAR-deficient phenotype, suggesting that the delayed flowering and SAR-deficient phenotypes are likely due to the same mutation. Analysis of $131 \mathrm{~F}_{2}$ progeny plants derived from the $r s i l \times$ WT Ws cross mapped $r s i l$ to the upper arm of chromosome 3, between the ChiB and LugSSLP467 molecular markers, 2.3 centimorgans from LugSSLP467. No recombinants were identified in the rsil-ChiB interval. A scan of the region between ChiB and LugSSLP467 for genes known to be associated with the transition from vegetative to reproductive stage identified FLD (At3g10390), which is located close to ChiB. Sequencing of the FLD locus from WT Col-0 and the rsil mutant identified a guanine to adenine $(\mathrm{G} \rightarrow \mathrm{A})$ transition in the first exon of FLD in the rsil mutant (Fig. 2A). Polymerase chain reaction (PCR) amplification with a set of modified primers that introduce an HpaII restriction site in the amplicon derived from WT Col-0 identified distinct restriction patterns in the WT compared with plants containing the rsil allele, thus confirming the presence of the $\mathrm{G} \rightarrow \mathrm{A}$ transition mutation in the FLD gene in the rsil mutant (Supplementary Fig. S3A). RSII/FLD expression was upregulated in the AvrPst-treated and distal leaves, further supporting FLD's involvement in SAR (Fig. 2B and C). 
FLD encodes a homolog of the human LYSINE-SPECIFIC DEMETHYLASE 1 and contains a Swi3p, Rsc8p, and Moira domain and a large polyamineoxidase domain (He et al. 2003). The rsil mutation results in a glycine to arginine substitution $\left(\mathrm{Gly}_{512} \rightarrow \mathrm{Arg}_{512}\right)$ in the polyamineoxidase domain of FLD (Fig. 2D). Gly $y_{512}$ is highly conserved among FLD homologs from a variety of organisms (Fig. 2D), suggesting that this is an important residue in these proteins. To further confirm that the SAR defect of rsil is, indeed, due to a mutation in $F L D$, SAR-conferred resistance against $P$. syringae pv. maculicola was characterized in additional loss-of-function alleles of FLD. Indeed, similar to rsil, compared with the WT, the SAR-conferred curtailment of $P$. syringae pv. maculicola population was weaker in the fld-3, fld-4, and fld-5 mutants (Fig. 2E and F). These results confirm an important role for $F L D$ in SAR.

\section{SAR-associated systemic SA accumulation is compromised in rsil.}

SAR is accompanied by a systemic increase in SA content in the pathogen-free leaves of plants that were locally treated with a SAR-inducing pathogen (Durrant and Dong 2004; Shah 2009). Furthermore, functional SA signaling is required for the activation of SAR-conferred resistance in the distal leaves. The distal leaves of WT plants, which were inoculated on their lower leaves with Avr-Pst, accumulated a higher level of SA (Fig. 3A and B). A comparable increase in systemic SA content was not observed in the rsil mutant (Fig. 3A and B). To determine whether loss of FLD function results in a general loss of ability to accumulate SA in response to biotic stress, SA content and expression of the SA-responsive PRI gene were determined in the primary pathogen-inoculated leaves. The rsil mutant retained the ability to accumulate elevated levels of SA and PRI transcript in the primary pathogen-inoculated leaves (Supplementary Figs. S4 and S5A), thus confirming that it does not have a general defect in SA accumulation. The rsil mutant also was not defective in SA perception or signaling because, like the WT plant, SA application enhanced resistance against $P$. syringae pv. maculicola in the rsil mutant (Fig. 3C). Taken together, these results suggest that the SA accumulation defect in rsil is limited to SAR.

Unlike the defect in SAR-associated systemic enhancement of SA content, the rsil mutant retained the SAR-associated upregulation of $P R 1$ in the distal pathogen-free tissues of plants that were inoculated on their lower leaves with Avr-Pst (Fig. 4A). In fact, the systemic induction of $P R I$ in the pathogen-free leaves was stronger in the rsil mutant compared with the WT plant. These results suggest that the SAR signal is being translocated from the pathogen-treated leaves to the distal leaves in rsil, resulting in the systemic increase in PRI transcript accumulation. Thus, the inability of rsil to express SAR-conferred enhanced disease resistance is due to defects in signaling affecting some of the responses to the SAR signal. Similarly, systemic induction of the ethylene- and jasmonicacid-responsive defense marker $P D F 1.2$ was also stronger in the rsil mutant than the WT plant (Fig. 4B). The elevated expression of $P R I$ in the pathogen-free distal tissue of rsil was unexpected and was in striking contrast to the lack of systemic SA accumulation and attenuated systemic resistance phenotype of the rsil mutant. Because SAR-expressing plants exhibit a more robust induction of SA signaling in response to challenge with pathogen, we compared PRI expression between the distal leaves of rsiland WT plants after challenge inoculation with $P$. syringae pv. maculicola. As expected, in WT plants, a stronger induction of $P R I$ expression was observed in the distal $P$. syringae pv. maculicola-challenged (secondary inoculation) leaves that were previously treated with Avr-Pst (primary inoculation) compared with the plants that received a primary inoculation consisting of $10 \mathrm{mM} \mathrm{MgCl}$ (Fig. 4C). However, a similar enhancement of $P R 1$ expression was not observed in the $P$. syringae pv. maculicola-challenged distal leaves of the rsil mutant that were previously (primary inoculation) inoculated on their lower leaves with Avr-Pst compared with $10 \mathrm{mM}$ $\mathrm{MgCl}_{2}$ (Fig. 4C). Even though the level of $P R l$ expression in the pathogen-free distal tissue of rsil was higher compared with comparably treated WT plants (Fig. 4A), this level is quantitatively much lower than in WT tissues exhibiting SARconferred enhanced disease resistance (Fig. 4C). The above results indicate that $F L D$ is not required for the expression of the $P R I$ gene in the distal tissue prior to secondary inoculation
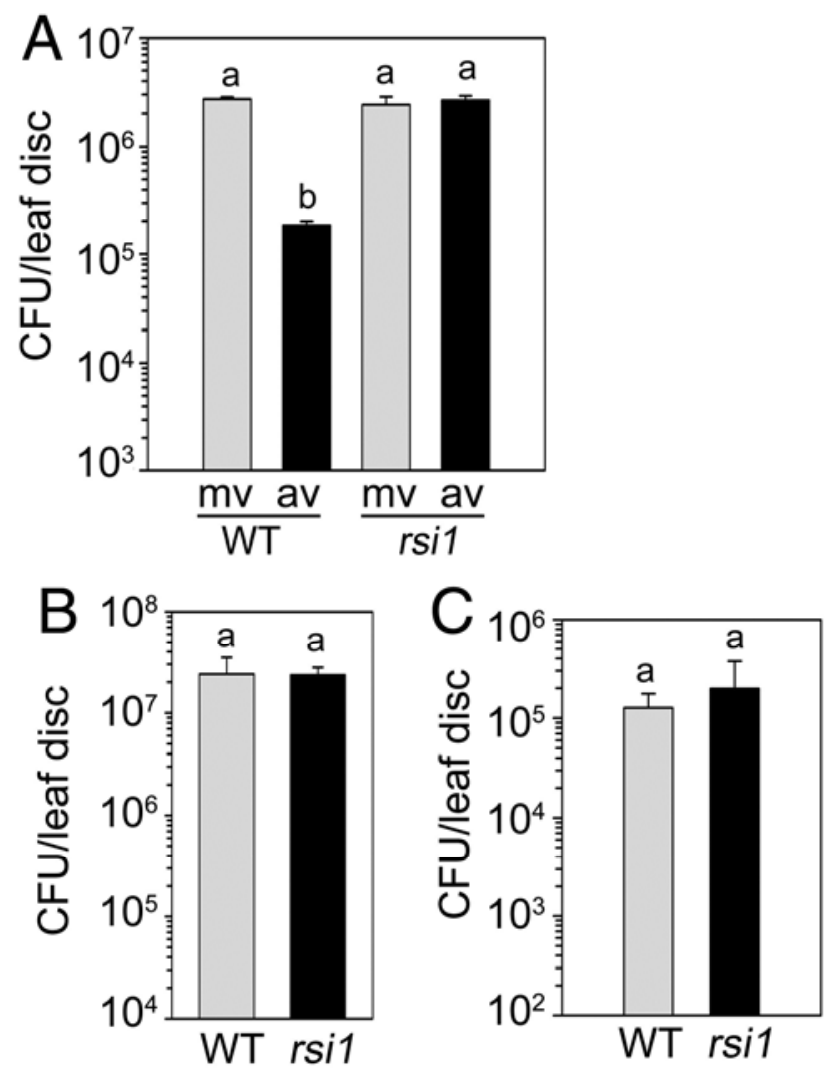

Fig. 1. Systemic acquired resistance (SAR) but not local resistance is compromised in the rsil mutant. A, SAR-conferred resistance in the wild type (WT) and the rsil mutant. A suspension $\left(10^{7} \mathrm{CFU} / \mathrm{ml}\right)$ of $P$. syringae pv. tomato DC3000 carrying AvrRpt2 (Avr-Pst) in $10 \mathrm{mM} \mathrm{MgCl}_{2}$ was infiltrated into the abaxial surface of three lower leaves with a needleless syringe. Plants that were similarly treated with $10 \mathrm{mM} \mathrm{MgCl}_{2}$ provided the mock controls for SAR. Three days later, four distal leaves of each plant received a challenge inoculation consisting of Pseudomonas syringae pv. maculicola ES4326 $\left(5 \times 10^{5} \mathrm{CFU} / \mathrm{ml}\right)$. . syringae pv. maculicola numbers in the distal leaves were determined 3 days postinfiltration (dpi). Bars: mv, primary treatment $=10 \mathrm{mM} \mathrm{MgCl}_{2}$ and secondary treatment $=P$. syringae pv. maculicola , av, primary treatment $=$ Avr-Pst and secondary treatment $=$ $P$. syringae pv. maculicola. B, Local defense against $P$. syringae pv. tomato DC3000 in the WT and the rsil mutant. A suspension of virulent pathogen $P$. syringae pv. tomato $\left(5 \times 10^{5} \mathrm{CFU} / \mathrm{ml}\right)$ was infiltrated into the abaxial surface of leaves with a needleless syringe. Bacterial numbers were determined at 3 dpi. C, Local defense against Avr-Pst in the WT and the $r$ sil mutant. A suspension of the avirulent pathogen Avr-Pst $\left(5 \times 10^{5}\right.$ $\mathrm{CFU} / \mathrm{ml}$ ) was infiltrated into the abaxial surface of leaves with a needleless syringe. Bacterial numbers were determined at 3 dpi. Each bar represents the mean \pm standard deviation of four samples, each carrying five leaf discs of $5 \mathrm{~mm}$ in diameter randomly taken from different plants. Letters above the bars indicate values that are significantly different $(P<$ 0.05 ) from each other as analyzed by one-way analysis of variance (posthoc Holm-Sidak method). Disease resistance studies were repeated three times, with similar results. 

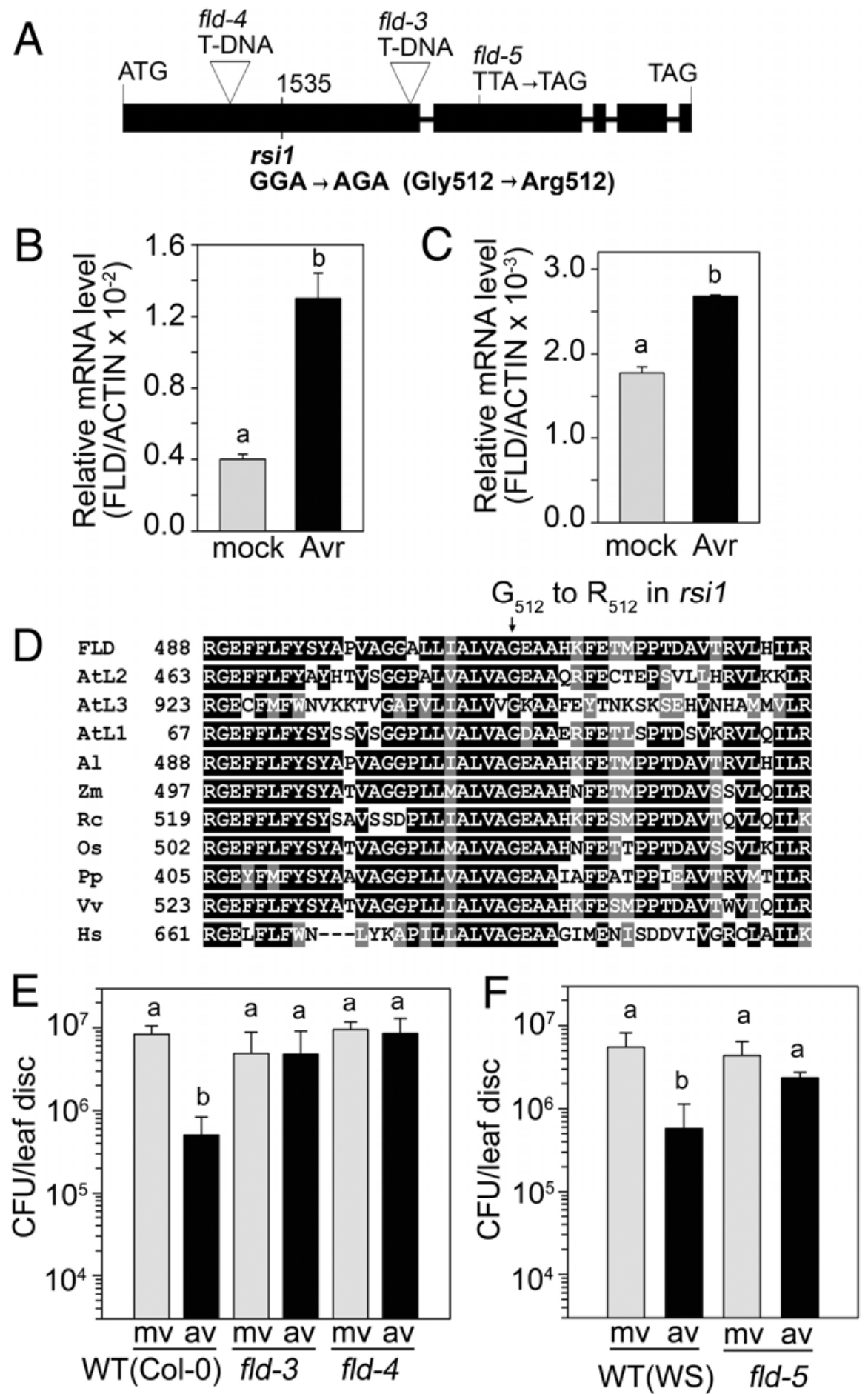

Fig. 2. rsil is a loss-of-function allele of $F L D$. A, RSI1/FLD gene structure with the relative position of mutation in each allele. Boxes and lines indicate exons and introns, respectively. Start and stop codons, position of point mutations associated with rsil (missense mutation) and fld-5(non-sense mutation), and sites of T-DNA insertions in $f l d-3$ and $f l d-4$ are indicated. B, Relative abundance of $F L D$ mRNA in leaves of wild-type (WT) plants, $12 \mathrm{~h}$ postinoculation with $P$. syringae pv. tomato DC3000 carrying AvrRpt2 (Avr-Pst) or $10 \mathrm{mM} \mathrm{MgCl}_{2}$. C, Relative abundance of $F L D$ mRNA in the distal leaves of WT plants that were previously (3 days earlier) treated on their lower leaves with Avr-Pst (Avr) or $10 \mathrm{mM} \mathrm{MgCl} 2$ (mock). D, Amino acid sequences surrounding Gly 512 of $F L D$ and close homologues in other eukaryotes. AtL1, AtL2, and AtL3 = Arabidopsis LSD1 like $(L D L)$ genes; $\mathrm{Al}=A$. lyrata; $\mathrm{Zm}=$ Zea mays; Rc = Ricinus communis; $\mathrm{Os}=$ Oryza sativa $; \mathrm{Pp}=$ Physcomitrella patens; $\mathrm{Vv}=$ Vitis venifera $; \mathrm{Hs}=$ Homo sapiens LSD1. $\mathrm{E}$, Pseudomonas syringae pv. maculicola numbers in the distal leaves of the WT (Col-0), fld-3, and fld-4 mutant plants that were previously treated on their lower leaves with Avr-Pst or $10 \mathrm{mM}$ $\mathrm{MgCl}_{2}$. F, P. syringae pv. maculicola numbers in the distal leaves of the WT (Ws) and fld-5 plants that were previously treated on their lower leaves with Avr-Pst or $10 \mathrm{mM} \mathrm{MgCl}_{2}$. B and $\mathbf{C}$, Real-time polymerase chain reaction was used to determine the abundance of the FLD transcript relative to the abundance of ACTIN 2 transcript. Each bar represents mean \pm standard deviation (SD) of three biological samples with two technical replications of each. The experiment was repeated two times, with similar results. $\mathbf{E}$ and $\mathbf{F}$, Challenge innoculation with $P$. syringae pv. maculicola was initiated by infiltrating the distal leaves with a suspension $\left(5 \times 10^{5} \mathrm{CFU} / \mathrm{ml}\right)$ of $P$. syringae pv. maculicola. Bacterial numbers were determined at 3 days postinfiltration. Each bar represents the mean \pm SD of four samples each carrying five leaf discs of $5 \mathrm{~mm}$ in diameter. Different letters above the bars indicate values that are significantly different $(P<0.05)$ from each other as analyzed by one-way analysis of variance (post-hoc Holm-Sidak method). Bars: mv, primary treatment $=$ $10 \mathrm{mM} \mathrm{MgCl} 2$ and secondary treatment $=P$. syringae pv. maculicola ; av, primary treatment $=$ Avr-Pst and secondary treatment $=P$. syringae pv. maculicola . Disease resistance studies were repeated three times, with similar results. 
but, rather, invokes stronger expression of $P R 1$ during the manifestation of SAR-associated enhanced disease resistance.

\section{$R S I 1 / F L D$ function is required for response}

to the long-distance SAR signal in the distal tissue.

The long-distance SAR signal can be recovered in Avr-Pex collected from Avr-Pst-inoculated leaves of WT plants (Chaturvedi et al. 2008, 2012; Jung et al. 2009; Maldonado et al. 2002). When applied to a few leaves of the WT plant, AvrPex is capable of protecting the distal leaves from subsequent infections. To determine whether rsil contains this SAR-activating factor, Avr-Pex collected from the rsil mutant was infiltrated into lower leaves of a WT plant. Three days later, the distal leaves were challenged with $P$. syringae pv. maculicola. Avr-Pex collected from WT plants provided the positive control. Avr-Pex from the WT and rsil mutant were equally effective in enhancing resistance against $P$. syringae pv. maculicola in the distal leaves of WT plants (Fig. 5A), suggesting that the rsil mutant produces the long-distance SAR signal. Next, we tested whether the rsil mutant was responsive to the SAR signal by applying Avr-Pex from WT plants to the lower leaves of the rsil mutant and challenging the distal leaves with $P$. syringae pv. maculicola. Avr-Pex collected from WT plants was unable to enhance resistance against $P$. syringae pv. maculicola in the distal leaves of the rsil mutant (Fig. 5A). DA and Aza applied to the lower leaves were also unable to enhance resistance against $P$. syringae pv. maculicola in the distal leaves of rsil compared with the WT plant (Fig. 5B). These results suggest that, in the rsil mutant, one or more processes that are required for SAR-conferred enhanced disease resistance are unable to respond to the SAR signals.

\section{FLD/RSII-mediated activation of SAR is independent of FLC function.}

The FLC gene, which is a target of the FLD-containing repressor complex, encodes a MADS box protein that negatively controls transition from vegetative growth to flowering by suppressing the transcription of genes that promote flowering (Michaels and Amasino 1999). In agreement with FLD negatively regulating $F L C$ expression, FLC transcripts accumulated at higher levels in the rsil mutant than the WT plant (Fig. 6A) and correlated with the delayed flowering phenotype of rsil, which was suppressed in the rsil flc double mutant (Fig. 6B). To determine whether the rsil-mediated SAR defect is linked to elevated FLC gene activity, SAR-conferred resistance to $P$. syringae pv. maculicola was monitored in the $f l c$ and $r$ sil flc double mutants. Like the WT, the flc mutant was SAR competent (Fig. 6C). By contrast, the rsil flc double mutant retained the SAR-deficient phenotype of the rsil single mutant (Fig. 6D; Supplementary Fig. S6). These results confirm that the $F L D$-mediated suppression of $F L C$ expression is critical for the transition to flowering but not for FLD's function during SAR.

\section{DISCUSSION}

We have shown that FLD is a critical player in SAR that is involved in signaling subsequent to the perception of the SAR
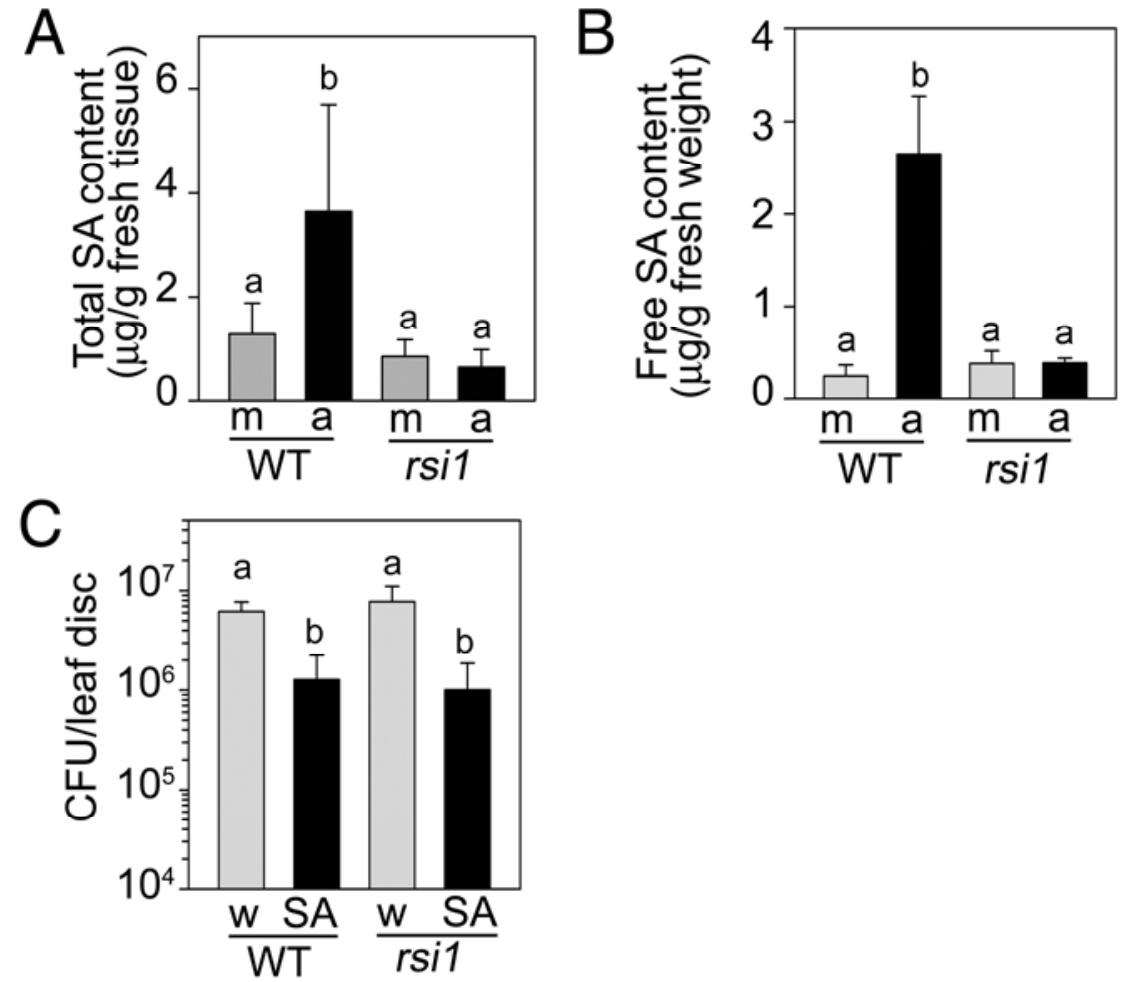

Fig. 3. Salicylic acid (SA) accumulation and response to SA application in the wild type (WT) and the rsil mutant. A, Total SA (Free SA + SA-glucoside) content in the distal leaves of WT and rsil plants 2 days after infiltration of $P$. syringae pv. tomato DC3000 carrying AvrRpt2 (Avr-Pst) (10 $\left.0^{7} \mathrm{CFU} / \mathrm{ml}\right)$ (a) or $10 \mathrm{mM} \mathrm{MgCl}_{2}(\mathrm{~m})$ into the lower leaves. B, Free SA content in the distal leaves of WT and rsil plants 2 days after infiltration of Avr-Pst (10 $\left.{ }^{7} \mathrm{CFU} / \mathrm{ml}\right)$ (a) or $10 \mathrm{mM} \mathrm{MgCl}_{2}(\mathrm{~m})$ into the lower leaves. C, Effect of exogenous SA application on Pseudomonas syringae pv. maculicola population in WT and rsil plants. Plants were either sprayed with $500 \mu \mathrm{M}$ SA dissolved in water or as a control with water (w). One day later, leaves were infiltrated with $P$. syringae pv. maculicola $\left(5 \times 10^{5} \mathrm{CFU} / \mathrm{ml}\right)$. P. syringae pv. maculicola numbers in these leaves were determined at 3 days postinfiltration. A and $\mathbf{B}$, Each bar represent mean \pm standard deviation (SD) of four samples, with each sample consisting $100 \mathrm{mg}$ of freshly harvested leaf samples. C, Each bar represents the mean \pm $\mathrm{SD}$ of four samples, each carrying five leaf discs of $5 \mathrm{~mm}$ in diameter from different leaves. Different letters above the bars indicate values that are significantly different $(P<0.05)$ from each other as analyzed by one-way analysis of variance (post-hoc Holm-Sidak method). Both SA accumulation and SA response studies were repeated two times, with similar results. 
signal. FLD expression was upregulated and FLD function was required for promoting disease resistance in the distal organs of plants which were previously inoculated on the lower leaves with a SAR-inducing microbe. Furthermore, Avr-Pex from WT leaves, as well as DA and Aza, were unable to systemically promote disease resistance in the rsil mutant, which contains a missense mutation in FLD. By contrast, comparable with WT Avr-Pex, local application of rsil Avr-Pex enhanced resistance against subsequent infections in the distal leaves of WT plants, thus confirming that the rsil mutant is not deficient in the synthesis or accumulation of the mobile SAR signals. Our results further suggest that a long-distance signal is delivered and perceived by the distal tissues of rsil, because $P R 1$ and $P D F 1.2$ transcript levels increased in the distal pathogen-free leaves of the rsil mutant in response to inoculation of the lower leaves with Avr-Pst. However, perception of this SAR signal was not sufficient to systemically promote disease resistance in mutant plants lacking FLD function. Absence of FLD function in rsil resulted in the attenuation of the SAR-associated systemic accumulation of SA and priming of the $P R I$ gene for stronger induction when subsequently challenged with the pathogen. However, the rsil mutation did not significantly impact SA accumulation in the Avr-Pst-treated leaves or basal resistance against virulent and avirulent pathogens, thus confirming that FLD's involvement in defense is limited to SAR. Exogenously applied SA was an effective inducer of disease resistance in rsil, therefore indicating that the rsil mutant is responsive to SA. We suggest that FLD function in SAR is required subse- quent to perception of the long-distance SAR signal and upstream of SA accumulation and priming of PRl genes in the pathogen-free distal leaves.

Increased accumulation of the PRI transcript has been extensively utilized as a molecular marker for the activation of SA signaling and SAR. However, despite the defect in systemic SA accumulation, $P R I$ transcript accumulated at elevated levels in the pathogen-free distal leaves of the rsil mutant that were inoculated on their lower leaves with Avr-Pst. Similar nonassociation between SAR-conferred enhanced disease resistance and systemic accumulation of $P R 1$ transcript have been reported for the $m p k 3$ and $h s f b l$ mutants (Beckers et al. 2009; Pick et al. 2012). Thus, although a good marker for studying activation of the SAR process, accumulation of the $P R I$ transcript in the distal tissue prior to secondary inoculation is not sufficient for SAR-conferred enhanced disease resistance. It is possible that a factor that negatively regulates $P R 1$ expression or promotes turnover of $P R 1$ transcript is lacking in the rsil mutant. In addition to positive regulatory elements, the $P R l$ promoter also contains negative regulatory elements which, when bound by the TGA 2 transcription factor in association with NPR1, negatively regulate $P R 1$ expression (Despres et al. 2000; Kesarwani et al. 2007). Indeed, activation of SA signaling resulted in higher levels of $P R 1$ transcript in the tga2 mutant than the WT plant (Rochon et al. 2006). However, despite the elevated PRI transcript accumulation, loss of tga2 was not sufficient to increase disease resistance (Zhang et al. 2003). It has also been suggested that induced expression of
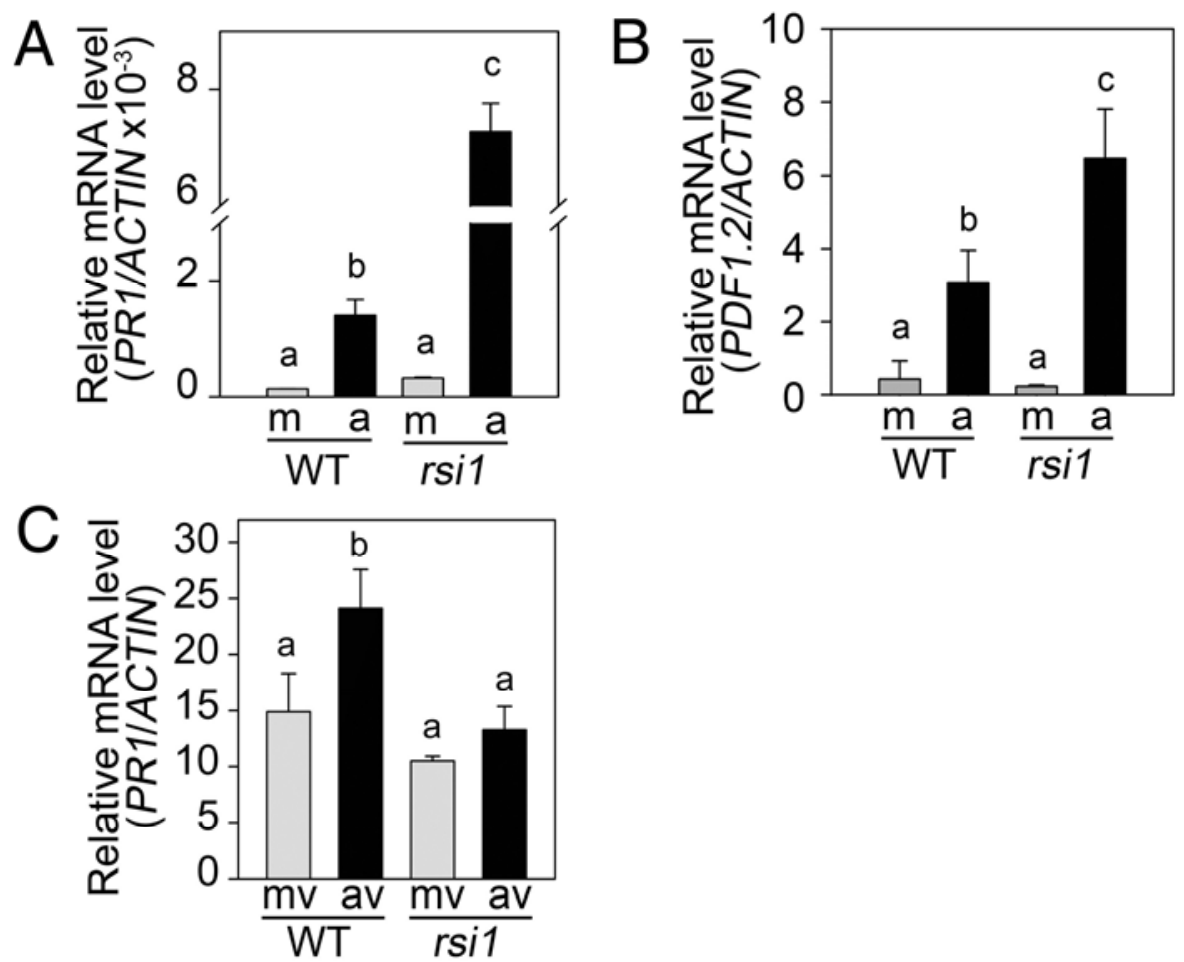

Fig. 4. Relative abundance of $P R 1$ transcript in wild-type (WT) and $r s i 1$ plants. A, Relative abundance of $P R 1$ transcript in the distal tissues of WT and $r s i 1$ plants 3 days after infiltration of lower leaves with $P$. syringae pv. tomato DC3000 carrying AvrRpt2 (Avr-Pst) $\left(10^{7} \mathrm{CFU} / \mathrm{ml}\right)(\mathrm{a}) \mathrm{or} 10 \mathrm{mM} \mathrm{MgCl} 2$ (m). B, Relative abundance of PDF1.2 transcript in the distal tissues of WT and rsil plants 3 days after infiltration of lower leaves with Avr-Pst ( $10^{7} \mathrm{CFU} / \mathrm{ml}$ ) (a) or $10 \mathrm{mM} \mathrm{MgCl}$ (m). C, Relative abundance of $P R 1$ transcript during systemic acquired resistance (SAR) exhibition in WT and rsil plants. Plants were inoculated on their lower leaves (primary treatment) with Avr-Pst $\left(10^{7} \mathrm{CFU} / \mathrm{ml}\right)$ or $10 \mathrm{mM} \mathrm{MgCl}$. Three days later, the distal leaves of these plants were challenged with Pseudomonas syringae pv. maculicola $\left(5 \times 10^{5} \mathrm{CFU} / \mathrm{ml}\right)$ (secondary treatment). The $P$. syringae pv. maculicola-inoculated leaves were harvested $24 \mathrm{~h}$ later for monitoring gene expression by real-time polymerase chain reaction (PCR). Bars: mv, primary treatment $=10 \mathrm{mM} \mathrm{MgCl}{ }_{2}$ and secondary treatment $=P$. syringae pv. maculicola ; av, primary treatment $=$ Avr-Pst and secondary treatment $=P$. syringae pv. maculicola . In A, B and $\mathbf{C}$ real-time PCR was used to determine the abundance of the PRI and PDF1.2 transcripts relative to the abundance of ACTIN 2 transcript. Each bar represents the mean \pm standard deviation of three biological samples with two technical replications of each. Different letters above the bars indicate values that are significantly different $(P$ $<0.05$ ) from each other as determined by one-way analysis of variance (post-hoc Holm-Sidak method). A and B, Experiments were repeated two times by taking rsil mutant, with similar results. C, Experiment was repeated two times with rsil and one time with fld-3 mutant, with similar results. 
$P R$ genes may not be sufficient for SAR because genes involved in protein folding, modification, and secretion also have to be coordinately upregulated for resistance (Wang et al. 2005).

FLD promotes flowering by downregulating expression of the flowering repressor FLC (Chou and Yang 1998; He et al. 2003; Kim and Sung 2012; Ruiqiang et al. 2005). Indeed, the delayed flowering phenotype of the rsil mutant was suppressed in the rsil flc double mutant, thus confirming that $f l c$ is epistatic to $r s i l$ during flowering. However, the SAR-deficient phenotype of rsil was retained in the rsil flc double mutant, thus indicating that FLD's involvement in SAR is independent of its role in regulation of FLC. Interestingly, SA has also been shown to promote flowering in Arabidopsis in an FLC-independent manner (Martinez et al. 2004). A delayed flowering phenotype was displayed by Arabidopsis accession Col-0 plants expressing the $n a h G$-encoded SA-degrading salicylate hydroxylase, and by the icsl (sid2) and eds5 (sidl) mutants (Martinez et al. 2004). The $n a h G$-determined delayed flowering phenotype was retained in the $n a h G$ flc plants, thus suggesting that the effect of SA on promoting flowering was independent of $F L C$ function (Martinez et al. 2004). In Arabidopsis, a few other defense-associated genes have been identified that influence flowering, as well. For example, flowering time is influenced by the ENHANCED DOWNY $M I L D E W 2$ (EDM2) gene, which is required for RPP7-mediated race-specific resistance to Hyaloperonospora arabidopsidis (Tsuchiya and Eulgem 2010). Flowering time was delayed in the edm2 mutant compared with the WT plant (Tsuchiya and Eulgem 2010). In contrast, mutations in the HOPW1-1-INTERACTING3 (WIN3) gene (also known as PBS3, GDG1, and GH3.12) that result in enhanced susceptibility to $P$. syringae and Botrytis cinerea and a modestly reduced SAR phenotype also result in early flowering under long-day conditions (Lee et al. 2007; Wang et al. 2011). WIN3, which encodes a protein in the firefly luciferase family, is required for promoting SA accumulation. However, whether the early flowering phenotype of the
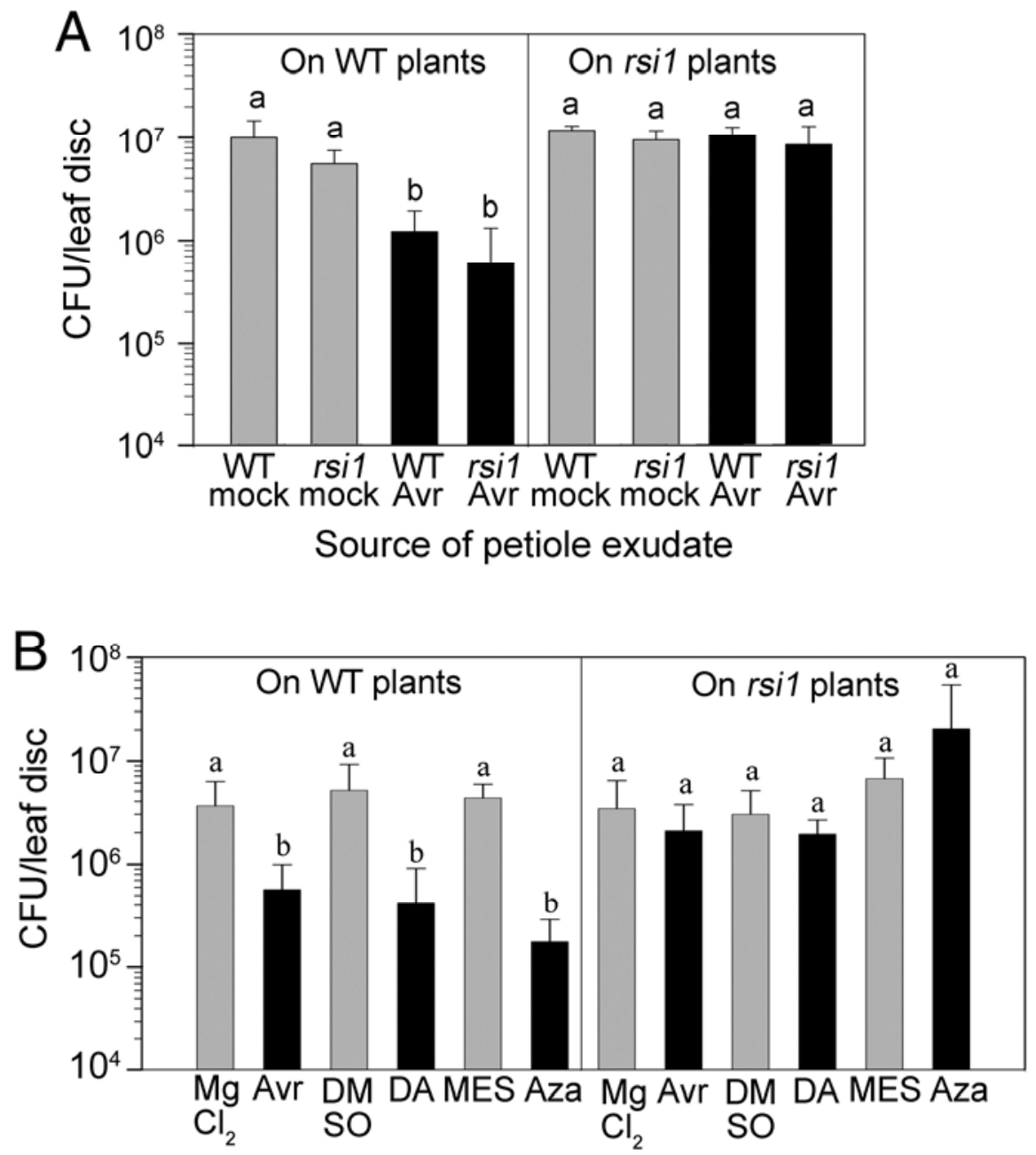

Fig. 5. Systemic acquired resistance (SAR) defect of the $r s i 1$ mutant is due to its inability to respond to the SAR signal. A, Effect of avirulence-petiole exudate (Avr-Pex) on SAR induction in the wild type (WT) and rsil plants. Leaves of WT and rsil plants were treated with P. syringae pv. tomato DC3000 carrying AvrRpt2 (Avr-Pst) $\left(10^{7} \mathrm{CFU} / \mathrm{ml}\right)$ or as a mock-treatment with $10 \mathrm{mM} \mathrm{MgCl}$. These Avr-Pst- and mock-treated leaves were detached and Pex collected from the cut ends of petioles. These Pex were infiltrated into lower leaves of naïve WT and rsil plants. Two days later, the distal leaves were challenged with Pseudomonas syringae pv. maculicola $\left(5 \times 10^{5} \mathrm{CFU} / \mathrm{ml}\right)$. P. syringae pv. maculicola numbers in these leaves were determined 3 days postinfiltration $(\mathrm{dpi})$. The experiment was repeated two times with rsil and two times with fld-3 mutant, with similar results. B, Effect of azelaic acid (Aza) and dehydroabietinal (DA) on SAR in WT and rsil plants. Three lower leaves of WT and rsil plants were infiltrated with Aza (1 mM) dissolved in $5 \mathrm{mM}$ morpholinoethanesulfonic acid (MES) buffer (pH 5.6) or DA (10 pM) dissolved in 0.1\% dimethyl sulfoxide (DMSO) or Avr-Pst (10 ${ }^{7}$ CFU/ml suspended in 10 $\mathrm{mM} \mathrm{MgCl} 2$ ). The control sets received $5 \mathrm{mM}$ MES ( $\mathrm{pH} 5.6$ ), $0.1 \%$ DMSO, or $10 \mathrm{mM} \mathrm{MgCl} 2$, respectively. After 2 days, the distal leaves were challenged with $P$. syringae pv. maculicola $\left(5 \times 10^{5} \mathrm{CFU} / \mathrm{ml}\right)$. P. syringae pv. maculicola numbers in these leaves were determined 3 dpi. Each bar represents the mean \pm standard deviation of four samples, each carrying five leaf discs of $5 \mathrm{~mm}$ in diameter. The experiment was repeated two times, with similar results. Different letters above the bars indicate values that are significantly different $(P<0.05)$ from each other as determined by one-way analysis of variance $($ post-hoc Holm-Sidak method). 
win3 mutant is related to its function in SA signaling is not known.

Recently, it was shown that SAR activation is accompanied by changes in chromatin at the promoter of some WRKY genes and priming of their expression by SA (Conrath 2011; Jaskiewicz et al. 2011; Luna et al. 2012). FLD is known to associate with histone demethylases and histone deacetylases to influence chromatin modification (He et al. 2003; Liu et al. 2007; Yu et al. 2011). Further work is needed to determine whether FLD is similarly involved in promoting chromatin alterations that accompany SAR.

\section{MATERIALS AND METHODS}

\section{Plant growth conditions.}

Plants were cultivated as previously described (Swain et al. 2011) with the following modifications. Arabidopsis was cultivated in a soil mixture containing soilrite and vermiculite $(5: 1)$ in a growth room that was set at 21 to $22^{\circ} \mathrm{C}$ and a regime of $12 \mathrm{~h}$ of light $\left(80 \mu \mathrm{E} \mathrm{m}^{-1} \mathrm{~s}^{-1}\right)$ and $12 \mathrm{~h}$ of darkness with $65 \%$ relative humidity, unless otherwise indicated. During transplantation and every 15 days thereafter, garden fertilizer mix (N-P-K, 20:20:20) was supplied along with irrigation water at $1 \mathrm{~g} /$ liter.

\section{SAR and local defense assay.}

SAR assays were performed as previously described (Maldonado et al. 2002; Nandi et al. 2004). In brief, overnight- grown Avr-Pst was infiltrated in lower three leaves of 5-weekold plants at $10^{7} \mathrm{CFU} / \mathrm{ml}$. Plants that were simultaneously treated with $10 \mathrm{mM} \mathrm{MgCl} 2$ were used as a mock control. Three days later, the distal leaves were challenged with $P$. syringae pv. maculicola $\left(10^{5} \mathrm{CFU} / \mathrm{ml}\right)$. P. syringae pv. maculicola counts were determined at 3 dpi by plating appropriate dilution of ground leaf extracts on media containing streptomycin. For determining the bacterial load in a given genotypic plant, four samples were prepared, with each sample containing five discs ( $5 \mathrm{~mm}$ in diameter) from different leaves. CFU numbers were directly used to determine the mean and standard deviations. To compare between the lines, the CFU values were $\log _{10}$ transformed and one-way analysis of variance was carried out by using Sigma-plot 11.0 software (post-hoc Holm-Sidak method). The local resistance studies were similar to that of SAR studies except that the plants were given no treatment prior to the pathogen inoculation.

\section{Mutagenesis and generation of double mutants.}

$\mathrm{M}_{2}$ population of ethylmethanesulfonate-treated Arabidopsis accession Col-0 plants was screened for the inability to activate SAR, as described previously (Nandi et al. 2003). The flc mutant (Salk_003346) was obtained from the Arabidopsis Biological Resource Centre at the Ohio State University (Columbus, OH, U.S.A.). Presence of the T-DNA was confirmed by PCR, with primers (Supplementary Table S2) designed with the T-DNA primer-designing tool available from the Salk Insti-
A
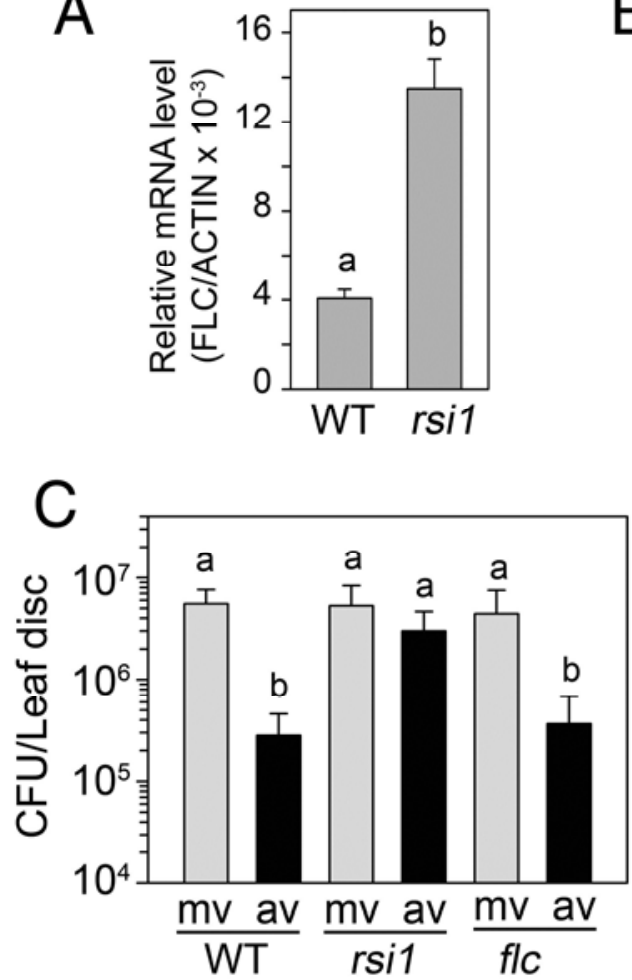
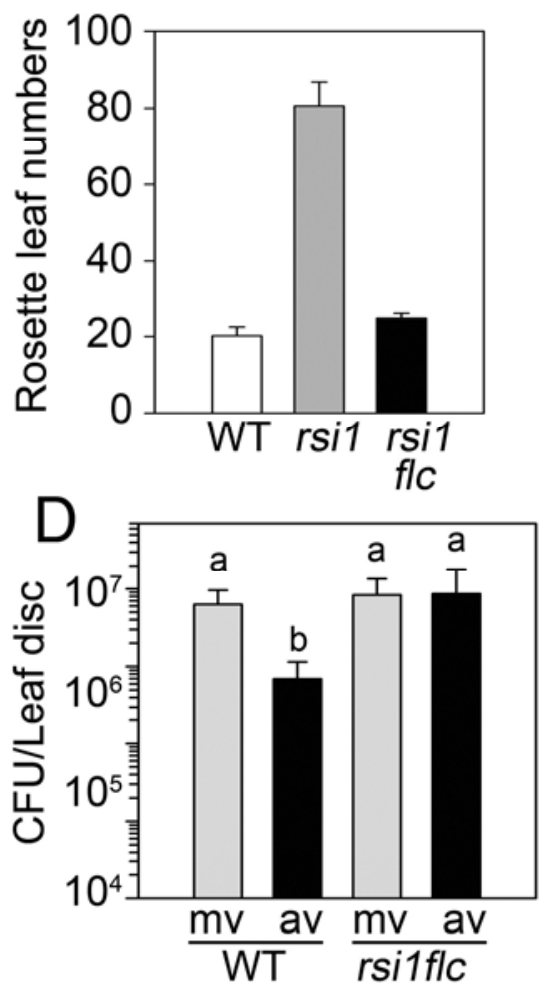

Fig. 6. FLC function is required for the rsil-conferred delayed flowering phenotype but not for systemic acquired resistance (SAR) deficiency. A, Relative abundance of the FLC transcript in leaves of the wild type (WT) and rsil plants. Real-time polymerase chain reaction was used to determine the abundance of the FLC transcript relative to the transcript abundance for ACTIN 2. Each bar represents the mean \pm standard deviation (SD) of three biological samples with two technical replications of each. B, Number of rosette leaves at the flowering stage in WT, $r s i l$, and $r s i l f l c$ plants that were grown under a cycle of $12 \mathrm{~h}$ of light and $12 \mathrm{~h}$ of darkness. C, Pseudomonas syringae pv. maculicola numbers in WT, rsil, and flc plants that were previously treated on their lower leaves with $P$. syringae pv. tomato DC3000 carrying AvrRpt2 (Avr-Pst) $\left(10^{7} \mathrm{CFU} / \mathrm{ml}\right.$ ) or $10 \mathrm{mM} \mathrm{MgCl} \mathrm{m}_{2}$. D, P. syringae pv. maculicola numbers in WT and rsil flc double-mutant plants that were previously treated on their lower leaves with Avr-Pst $\left(10^{7} \mathrm{CFU} / \mathrm{ml}\right)$ or $10 \mathrm{mM} \mathrm{MgCl} 2 . \mathbf{C}$ and $\mathbf{D}$, Challenge inoculation with $P$. syringae pv. maculicola was initiated by infiltrating the distal leaves with a suspension $\left(5 \times 10^{5} \mathrm{CFU} / \mathrm{ml}\right)$ of $P$. syringae pv. maculicola. Bacterial numbers were determined at 3 days postinfiltration (dpi). Each bar represents the mean \pm SD of four samples, each carrying five leaf discs of 5 mm in diameter. Different letters above the bars indicate values that are significantly different $(P<0.05)$ from each other as analyzed by one-way analysis of variance (post-hoc Holm-Sidak method). Bars: mv, primary treatment $=10 \mathrm{mM} \mathrm{MgCl}$ and secondary treatment $=$ P. syringae pv. maculicola; av, primary treatment $=$ Avr-Pst and secondary treatment $=P$. syringae pv. maculicola. Experiments were repeated two $(\mathrm{A}$ and $\mathrm{B})$ or three $(\mathrm{C}$ and $\mathrm{D})$ times, with similar results. 
tute of Genome Analysis Laboratory. The rsil mutant was crossed with the $f l c$ mutant and a segregating $\mathrm{F}_{2}$ population was screened for double mutants by PCR with primers that could distinguish each mutant allele from the corresponding WT allele. Out of a total of $16 \mathrm{~F}_{2}$ plants tested, plants number 10 and 18 were double mutants because they showed only rsil-specific bands after HpaII digestion, showed presence of T-DNA, and failed to generate WT FLC-specific bands, indicating that they were homozygous for the mutant $f l c$ allele (Supplementary Fig. S7). The rsil flc double mutant phenotype was further confirmed by monitoring the early flowering phenotype conferred by the rsil allele.

\section{Collection of Pex and induction of SAR.}

Pex were collected using a modified version of our published protocol (Chaturvedi et al. 2008). WT and rsil plants were infiltrated with $P$. syringae pv. tomato DC3000 carrying AvrRpt2 $\left(10^{7} \mathrm{CFU} / \mathrm{ml}\right)$ or $10 \mathrm{mM} \mathrm{MgCl}_{2}$ (mock). Plants were kept in a growth room covered with a plastic dome for $6 \mathrm{~h}$. The infiltrated leaves were cut at the base of the petioles with a sharp scissor and immediately surface sterilized by dipping in $50 \%$ ethanol and $0.0006 \%$ bleach for $10 \mathrm{~s}$. The Pex were collected by dipping the cut end of the petioles in $1.5 \mathrm{ml}$ of $1 \mathrm{mM}$ EDTA ( $\mathrm{pH} \mathrm{8.0)} \mathrm{solution} \mathrm{contained} \mathrm{in} \mathrm{24-well} \mathrm{tissue} \mathrm{culture}$ plates. Five harvested leaves were placed in each well and a batch of 50 to 70 leaves was processed each time. After $24 \mathrm{~h}$ of collection, exudates were filtered with a $0.2-\mu \mathrm{M}$ syringe filter (MDI, Ambala Cantt, India) and diluted twofold with sterile water. The collected Avr-Pex and, as a negative control, the Mock-Pex were infiltrated with a needleless-syringe into the lower three leaves of naive plants to induce SAR. Secondary challenge inoculations, when required, involved infiltration of the virulent pathogen $P$. syringae pv. maculicola ES4326.

\section{SA estimation.}

SA extraction from ground Arabidopsis leaves $(100 \mathrm{mg})$ was carried out twice with $0.8 \mathrm{ml}$ of $80 \%$ methanol and once with $0.8 \mathrm{ml}$ of $100 \%$ methanol in $1.5-\mathrm{ml}$ centrifuge tubes as previously described (Nandi et al. 2004). To the extracts, $20 \mu \mathrm{l}$ of $0.2 \mathrm{M} \mathrm{NaOH}$ was added to minimize sublimation of SA during drying (Verberne et al. 2002). The extracts were dried under speed vac by keeping 30 to $40 \mu \mathrm{l}$ of liquid in the tubes and resuspended in $500 \mu \mathrm{l}$ of sodium-acetate buffer $(0.1 \mathrm{M}, \mathrm{pH}$ 5.2) by vortexing thoroughly and by sonicating in the water bath sonicator for $16 \mathrm{~min}$. The content was divided into two halves, one for free SA and the other for total SA. For estimating total SA, $50 \mu \mathrm{l}$ of $\beta$-galactosidase $(40-\mathrm{mg} / \mathrm{ml}$ stock prepared in 0.1 M NaOAc, pH 5.2; Sigma catalog number G0395) was added to each tube and incubated for $2 \mathrm{~h}$ at $37^{\circ} \mathrm{C}$ (Defraia et al. 2008). The free-SA tubes were left at room temperature without any treatment. Trichloroacetic acid (final concentration $5 \%$ ) was added to all the tubes and precipitates were removed by centrifugation. SA was extracted by partitioning with a mixture of $0.8 \mathrm{ml}$ of cyclohexane and ethylacetate $(1: 1)$ two times. To the extracts, $60 \mu \mathrm{l}$ of mobile phase $(0.2 \mathrm{M}$ $\mathrm{NaOAC}$ [pH 5.2] and $10 \%$ methanol) was added and dried under speed vac by keeping 30 to $40 \mu \mathrm{l}$ of liquid in the tubes (Verberne et al. 2002). The samples were dissolved in $200 \mu \mathrm{l}$ of mobile phase and $100 \mu \mathrm{l}$ was analyzed through high-performance liquid chromatography (HPLC Agilent 1220 LC) by passing over a $5-\mu \mathrm{m} \mathrm{C} 18$ reverse-phase column (4.6 by 150 $\mathrm{mm}$ ) at the flow rate of $0.8 \mathrm{ml} / \mathrm{min}$ and detection by UV at 310 nm. For generating SA standard curve, pure SA (Sigma catalog number S7401) dissolved in methanol at different concentrations (three replicates for each concentration) was followed by the method described above.

\section{Chemical treatment.}

DA was prepared as a $10-\mathrm{pM}$ solution in $0.1 \%$ dimethyl sulfoxide (Chaturvedi et al. 2012) and Aza was prepared as a 1$\mathrm{mM}$ solution in $5 \mathrm{mM}$ morpholinoethanesulfonic acid buffer, pH 6.5 (Jung et al. 2009). These solutions were infiltrated with a needleless syringe into three lower leaves to induce SAR. SAR assays were carried out as mentioned above.

\section{mRNA expression analysis by real-time PCR.}

Total RNA was isolated from leaf samples with a mix of guanidine-phenol-chloroform, as previously described (Chomczynski and Sachhi 1987). cDNA synthesis was carried out with Moloney murine leukemia virus reverse-transcriptase (MBI Fermentas, Amherst NY, U.S.A.). Relative quantity of mRNA for each gene was plotted as fold difference with ACTIN2 (At3g18780). Real-time PCR was carried out by a 7500 Fast Real-Time PCR machine (Applied Biosystems, Foster City, CA, U.S.A.) using Power SYBR Green master mix (Applied Biosystems). All analyses were with the system software v2.0.5. Specificity of each primer set was validated by sequencing the amplified product. A nontemplate control was included in all real-time PCR reactions. The melting curve generated by the real-time software was followed to ensure the presence of a single product in each lane.

\section{ACKNOWLEDGMENTS}

We thank R. Amasino for fld-3 and fld-4, Z. Jinaro for fld-5, the Arabidopsis Biological Resource Centre for the flc seed, U. Nath for comments and help with manuscript preparation, and S. Swain for helpful discussions. This work is supported by Department of Biotechnology (DBT) grant (BT/PR14656/BRB/10/864/2010) to A. K. Nandi, Indian Council of Medical Research fellowship to M. K. Giri, Council of Scientific and Industrial Research fellowship to S. Roy, and a grant from the National Science Foundation (IOS-1121570) to J. Shah. Designing of experiments, A. K. Nandi and J. Shah; screening of EMS population, V. Singh and A. K. Nandi; disease resistance studies and identification of rsil, rsil flc doublemutant generation, V. Singh; expression of FLD, FLC, and defense-related genes, V. Singh, S. Roy, and M. K. Giri; SAR assay with DA and Aza, R. Chaturvedi; SA analysis, Z. Chowdhury, V. Singh, and A. K. Nandi; manuscript writing, all authors.

\section{LITERATURE CITED}

Attaran, E., Zeier, T. E., Griebel, T., and Zeier, J. 2009. Methyl salicylate production and jasmonate signaling are not essential for systemic acquired resistance in Arabidopsis. Plant Cell 21:954-971.

Beckers, G. J., Jaskiewicz, M., Liu, Y., Underwood, W. R., He, S. Y., Zhang, S., and Conrath, U. 2009. Mitogen-activated protein kinases 3 and 6 are required for full priming of stress responses in Arabidopsis thaliana. Plant Cell 21:944-953.

Chanda, B., Xia, Y., Mandal, M. K., Yu, K., Sekine, K. T., Gao, Q. M., Selote, D., Hu, Y., Stromberg, A., Navarre, D., Kachroo, A., and Kachroo, P. 2011. Glycerol-3-phosphate is a critical mobile inducer of systemic immunity in plants. Nat. Genet. 43:421-427.

Chaturvedi, R., and Shah, J. 2007. Salicylic acid in plant disease resistance. Pages 335-370 in: Salicylic Acid-A Plant Hormone. S. Hayat and A. Ahmad, eds. Springer, Dordrecht, The Netherlands.

Chaturvedi, R., Krothapalli, K., Makandar, R., Nandi, A., Sparks, A. A., Roth, M. R., Welti, R., and Shah, J. 2008. Plastid omega3-fatty acid desaturase-dependent accumulation of a systemic acquired resistance inducing activity in petiole exudates of Arabidopsis thaliana is independent of jasmonic acid. Plant J. 54:106-117.

Chaturvedi, R., Venables, B., Petros, R. A., Nalam, V., Li, M., Wang, X., Takemoto, L. J., and Shah, J. 2012. An abietane diterpenoid is a potent activator of systemic acquired resistance. Plant J. 71:161-172.

Chomczynski, P., and Sachhi, N. 1987. single step method of RNA isolation by acid guanidinium thiocyanate-phenol-chloroform extraction. Anal. Biochem. 162:156-159.

Chou, M. L., and Yang, C. H. 1998. FLD interacts with genes that affect different developmental phase transitions to regulate Arabidopsis shoot development. Plant J. 15:231-242.

Conrath, U. 2011. Molecular aspects of defence priming. Trends Plant Sci. 16:524-531. 
Defraia, C. T., Schmelz, E. A., and Mou, Z. 2008. A rapid biosensor-based method for quantification of free and glucose-conjugated salicylic acid. Plant Methods 4:28.

Dempsey, D. A., and Klessig, D. F. 2012. SOS — too many signals for systemic acquired resistance? Trends Plant Sci. 17:538-545.

Despres, C., DeLong, C., Glaze, S., Liu, E., and Fobert, P. R. 2000. The Arabidopsis NPR1/NIM1 protein enhances the DNA binding activity of a subgroup of the TGA family of bZIP transcription factors. Plant Cell $12: 279-290$

Durrant, W. E., and Dong, X. 2004. Systemic acquired resistance. Annu. Rev. Phytopathol. 42:185-209.

Guedes, M. E. M., Richmond, S., and Kuc, J. 1980. Induced systemic resistance to anthracnose in cucumber as influenced by the location of the inducer inoculation with Colletotrichum lagenarium and the onset of flowering and fruiting Physiol. Plant Pathol. 17:229-233.

He, Y., Michaels, S. D., and Amasino, R. M. 2003. Regulation of flowering time by histone acetylation in Arabidopsis. Science 302:1751-1754.

Jaskiewicz, M., Conrath, U., and Peterhansel, C. 2011. Chromatin modification acts as a memory for systemic acquired resistance in the plant stress response. EMBO (Eur. Mol. Biol. Organ.) Rep. 12:50-55.

Jung, H. W., Tschaplinski, T. J., Wang, L., Glazebrook, J., and Greenberg, J. T. 2009. Priming in systemic plant immunity. Science 324:89-91.

Kesarwani, M., Yoo, J., and Dong, X. 2007. Genetic interactions of TGA transcription factors in the regulation of pathogenesis-related genes and disease resistance in Arabidopsis. Plant Physiol. 144:336-346.

Kim, D. H., and Sung, S. 2012. Environmentally coordinated epigenetic silencing of FLC by protein and long noncoding RNA components. Curr. Opin. Plant Biol. 15:51-56.

Lawton, K., Weymann, K., Friedrich, L., Vernooij, B., Uknes, S., and Ryals, J. 1995. Systemic acquired resistance in Arabidopsis requires salicylic acid but not ethylene. Mol. Plant-Microbe Interact. 8:863-870.

Lee, M. W., Lu, H., Jung, H. W., and Greenberg, J. T. 2007. A key role for the Arabidopsis WIN3 protein in disease resistance triggered by Pseudomonas syringae that secretes AvrRpt2. Mol. Plant-Microbe Interact. 20:1192-1200.

Liu, F., Quesada, V., Crevillen, P., Baurle, I., Swiezewski, S., and Dean, C. 2007. The Arabidopsis RNA-binding protein FCA requires a lysinespecific demethylase 1 homolog to downregulate FLC. Mol. Cell 28:398-407

Liu, P. P., von Dahl, C. C., and Klessig, D. F. 2011. The extent to which methyl salicylate is required for signaling systemic acquired resistance is dependent on exposure to light after infection. Plant Physiol. 157:2216-2226.

Lorenc-Kukula, K., Chaturvedi, R., Roth, M., Welti, R., and Shah, J. 2012. Biochemical and molecular-genetic characterization of SFD1's involvement in lipid metabolism and defense signaling. Front. Plant Sci. 3:26.

Luna, E., Bruce, T. J., Roberts, M. R., Flors, V., and Ton, J. 2012. Nextgeneration systemic acquired resistance. Plant Physiol. 158:844-853.

Maldonado, A. M., Doerner, P., Dixon, R. A., Lamb, C. J., and Cameron, R. K. 2002. A putative lipid transfer protein involved in systemic resistance signalling in Arabidopsis. Nature 419:399-403.

Manosalva, P. M., Park, S. W., Forouhar, F., Tong, L., Fry, W. E., and Klessig, D. F. 2010. Methyl esterase 1 (StMES1) is required for systemic acquired resistance in potato. Mol. Plant-Microbe Interact. 23:1151-1163.

Martinez, C., Pons, E., Prats, G., and Leon, J. 2004. Salicylic acid regulates flowering time and links defence responses and reproductive development. Plant J. 37:209-217.

Michaels, S. D., and Amasino, R. M. 1999. FLOWERING LOCUS C encodes a novel MADS domain protein that acts as a repressor of flowering. Plant Cell 11:949-956.

Nandi, A., Krothapalli, K., Buseman, C. M., Li, M., Welti, R., Enyedi, A., and Shah, J. 2003. Arabidopsis sfd mutants affect plastidic lipid composition and suppress dwarfing, cell death, and the enhanced disease resistance phenotypes resulting from the deficiency of a fatty acid desaturase. Plant Cell 15:2383-2398.

Nandi, A., Welti, R., and Shah, J. 2004. The Arabidopsis thaliana dihydroxyacetone phosphate reductase gene SUPPRESSSOR OF FATTY ACID DESATURASE DEFICIENCY1 is required for glycerolipid metabolism and for the activation of systemic acquired resistance. Plant Cell 16:465-477.

Navarova, H., Bernsdorff, F., Doring, A. C., and Zeier, J. 2012. Pipecolic acid, an endogenous mediator of defense amplification and priming, is a critical regulator of inducible plant immunity. Plant Cell 24:5123-5141.

Pallas, J. A., Paiva, N. L., Lamb, C., and Dixon, R. A. 1996. Tobacco plants epigenetically suppressed in phenylalanine ammonia-lyase expression do not develop systemic acquired resistance in response to infection by tobacco mosaic virus. Plant J. 10:281-293.

Park, S. W., Kaimoyo, E., Kumar, D., Mosher, S., and Klessig, D. F. 2007. Methyl salicylate is a critical mobile signal for plant systemic acquired resistance. Science 318:113-116.

Pick, T., Jaskiewicz, M., Peterhansel, C., and Conrath, U. 2012. Heat shock factor HsfB1 primes gene transcription and systemic acquired resistance in Arabidopsis. Plant Physiol. 159:52-55.

Rasmussen, J. B., Hammerschmidt, R., and Zook, M. N. 1991. Systemic induction of salicylic acid accumulation in cucumber after inoculation with Pseudomonas syringae pv. syringae. Plant Physiol. 97:1342-1347.

Rochon, A., Boyle, P., Wignes, T., Fobert, P. R., and Despres, C. 2006. The coactivator function of Arabidopsis NPR1 requires the core of its BTB/POZ domain and the oxidation of C-terminal cysteines. Plant Cell 18:3670-3685.

Ruiqiang, C., Suzhi, Z., Shulan, S., Jianhong, C., and Jianru, Z. 2005. Characterization of a new mutant allele of the Arabidopsis flowering locus D. Chin. Sci. Bull. 50:2701-2706.

Shah, J. 2009. Plants under attack: Systemic signals in defence. Curr. Opin. Plant Biol. 12:459-464.

Shah, J., and Zeier, J. 2013. Long-distance communication and signal amplification in systemic acquired resistance. Front. Plant Sci. 4:30.

Spoel, S. H., and Dong, X. 2012. How do plants achieve immunity? Defence without specialized immune cells. Nat. Rev. Immunol. 12:89-100.

Sticher, L., Mauch-Mani, B., and Metraux, J. P. 1997. Systemic acquired resistance. Annu. Rev. Phytopathol. 35:235-270.

Swain, S., Roy, S., Shah, J., Van Wees, S., Pieterse, C. M., and Nandi, A. K. 2011. Arabidopsis thaliana cdd1 mutant uncouples the constitutive activation of salicylic acid signalling from growth defects. Mol. Plant Pathol. 12:855-865

Traw, M. B., Kniskern, J. M., and Bergelson, J. 2007. SAR increases fitness of Arabidopsis thaliana in the presence of natural bacterial pathogens. Evolution 61:2444-2449.

Tsuchiya, T., and Eulgem, T. 2010. The Arabidopsis defense component EDM2 affects the floral transition in an FLC-dependent manner. Plant J. 62:518-528.

Tuzun, S., and Kuc, J. 1985. Movement of a factor in tobacco infected with Peronospora tabacina Adam which systemically protect against blue mold. Physiol. Plant Pathol. 26:321-330.

Verberne, M. C., Brouwer, N., Delbianco, F., Linthorst, H. J., Bol, J. F., and Verpoorte, R. 2002. Method for the extraction of the volatile compound salicylic acid from tobacco leaf material. Phytochem. Anal. 13:45-50.

Vernooij, B., Friedrich, L., Morse, A., Reist, R., Kolditz-Jawhar, R., Ward, E., Uknes, S., Kessmann, H., and Ryals, J. 1994. Salicylic acid Is not the translocated signal responsible for inducing systemic acquired resistance but is required in signal transduction. Plant Cell 6:959-965.

Vlot, A. C., Liu, P. P., Cameron, R. K., Park, S. W., Yang, Y., Kumar, D., Zhou, F., Padukkavidana, T., Gustafsson, C., Pichersky, E., and Klessig, D. F. 2008. Identification of likely orthologs of tobacco salicylic acidbinding protein 2 and their role in systemic acquired resistance in Arabidopsis thaliana. Plant J. 56:445-456.

Wang, D., Weaver, N. D., Kesarwani, M., and Dong, X. 2005. Induction of protein secretory pathway is required for systemic acquired resistance. Science 308:1036-1040.

Wang, G. F., Seabolt, S., Hamdoun, S., Ng, G., Park, J., and Lu, H. 2011. Multiple roles of WIN3 in regulating disease resistance, cell death, and flowering time in Arabidopsis. Plant Physiol. 156:1508-1519.

Wildermuth, M. C., Dewdney, J., Wu, G., and Ausubel, F. M. 2001. Isochorismate synthase is required to synthesize salicylic acid for plant defence. Nature 414:562-565.

Wu, Y., Zhang, D., Chu, J. Y., Boyle, P., Wang, Y., Brindle, I. D., De Luca, V., and Despres, C. 2012. The Arabidopsis NPR1 protein is a receptor for the plant defense hormone salicylic acid. Cell Rep. 1:639-647.

Yu, C. W., Liu, X., Luo, M., Chen, C., Lin, X., Tian, G., Lu, Q., Cui, Y., and Wu, K. 2011. HISTONE DEACETYLASE6 interacts with FLOW ERING LOCUS D and regulates flowering in Arabidopsis. Plant Physiol. 156:173-184.

Zhang, Y., Tessaro, M. J., Lassner, M., and Li, X. 2003. Knockout analysis of Arabidopsis transcription factors TGA2, TGA5, and TGA6 reveals their redundant and essential roles in systemic acquired resistance. Plant Cell 15:2647-2653

\section{AUTHOR-RECOMMENDED INTERNET RESOURCES}

The Arabidopsis Information Resource website: www.arabidopsis.org Salk Institute of Genome Analysis website: signal.salk.edu 